\title{
Trends in Scientific Literature on Energy Return Ratio of Renewable Energy Sources for Supporting Policymakers
}

\author{
Roberto Leonardo Rana ${ }^{1}\left(\mathbb{D}\right.$, Mariarosaria Lombardi $^{1}\left(\mathbb{D}\right.$, , Pasquale Giungato $^{2, *}$ (D) and \\ Caterina Tricase ${ }^{1}$ (D) \\ 1 Department of Economics, University of Foggia, 71122 Foggia, Italy; roberto.rana@unifg.it (R.L.R.); \\ mariarosaria.lombardi@unifg.it (M.L.); caterina.tricase@unifg.it (C.T.) \\ 2 Department of Chemistry, University of Bari, 70125 Bari, Italy \\ * Correspondence: pasquale.giungato@uniba.it
}

Received: 19 February 2020; Accepted: 26 March 2020; Published: 29 March 2020

\begin{abstract}
The scarcity of fossil fuels and their environmental impact as greenhouse gas (GHG) emissions, have prompted governments around the world to both develop research and foster the use of renewable energy sources (RES), such as biomass, wind, and solar. Therefore, although these efforts represent potential solutions for fossil fuel shortages and GHG emission reduction, some doubts have emerged recently regarding their energy efficiency. Indeed, it is very useful to assess their energy gain, which means quantifying and comparing the amount of energy consumed to produce alternative fuels. In this context, the aim of this paper is to analyze the trend of the academic literature of studies concerning the indices of the energy return ratio (ERR), such as energy return on energy invested (EROEI), considering biomass, wind and solar energy. This could be useful for institutions and to public organizations in order to redefine their political vision for realizing sustainable socio-economic systems in line with the transition from fossil fuels to renewable energies. Results showed that biomass seems to be more expensive and less efficient than the equivalent fossil-based energy, whereas solar photovoltaic (PV) and wind energy have reached mature and advanced levels of technology.
\end{abstract}

Keywords: energy efficiency; renewable energy sources; energy return ratio; EROEI

\section{Introduction}

Energy plays a fundamental role in systems, as it allows for the operation and, consequently, the transfer of information among its components. In an economic system, it allows for human development. In a society, the availability and quality of various types of energy and material resources drive growth, the settlement of people, and the eventual decline experienced by each civilization (Hall et al. 2014). For 200 years, fossil fuels have represented dominant sources of energy, powering human societies and contributing to prosperity across fields, such as economics, agriculture, transportation, and the sciences. According to British Petroleum (2019), in 2018, the primary world energy consumption was equal to 13.9 Gtoe, and fossil fuels, such as oil, natural gas, and coal, contributed $84.7 \%$ of the total. This was followed by hydroelectricity $(6.8 \%)$, nuclear energy $(4.4 \%)$, and other renewables such as wind, geothermal, solar, biomass, and waste $(4.1 \%)$.

Although renewable energy sources (RES) satisfy a small percentage of global primary energy demand, their importance has been increasing in most countries due to unquestionable environmental and social benefits (lower greenhouse gas (GHG) emissions that result in mitigating climate change) and the possibility to be managed at local and participative level (Lyu and Shi 2018; Capellán-Pérez et al. 2019). Numerous strategies have been adopted to mitigate GHG emissions 
with an administrative science approach in the form of green information technology and green information systems (Imasiku et al. 2019). Moreover, governments are addressing the effects of climate change and managing the associated transition to a larger share of renewable energy-based generation (Chapman et al. 2016).

Therefore, the transition from fossil fuels to renewable energies is a crucial condition for realizing sustainable socio-economic systems even if, currently, the performance of RES technologies can be, in some cases, worse than those of fossil fuels (Murphy and Hall 2010; Capellán-Pérez et al. 2019). Actually, scientists and economists have already proved that, in energy production processes, the quantity of energy delivered (energy output) by renewable sources is often less than or is equal to energy consumed in capturing and delivering it to customers (energy input) (Heinberg and Mander 2009). Hence, the technologies to produce renewable energies are not sufficiently mature enough to replace fossil fuels in terms of energy gain. This means that policymakers should implement policies and strategies to support, financially, the improvement of their energy efficiency for the socio-economic and technical consequences of their large-scale replacement in the energy system.

In this context, it could be very useful to provide information to institutions and/or public organizations about the current state of the art of RES energy efficiency to help them to redefine their political vision (Clack et al. 2017) for realizing sustainable socio-economic systems, in line with the transition from fossil fuels to renewable energies.

Consequently, the aim of this paper is to offer a critical analysis of the academic literature of studies concerning the EE indices of RES in the last 20 years, in order to present the state of the art in this field and identify recent research and energy efficiency trends.

The authors point out that the paper does not represent a systematic review due to the encountered methodological limits, mainly related to the heterogeneity of the contents of the bibliographic sources.

Specifically, the authors will focus on the energy return ration (ERR) and some its typologies, such as the net energy ratio (NER) or renewability factor (RF), the net energy gain (NEG) or net energy value (NEV), and the energy returned on investment (EROEI) applied to biomass, solar and wind energy. They will not consider hydroelectric power production, since it is a mature technology and the possibility of improving further its energy efficiency is limited (Fagnart et al. 2020). The reason of this choice is due to the fact that these indices are able to assess the amount of useful energy that remains after energy consumed to drill, pipe, refine, or build infrastructure (including solar panels, wind turbines, dams, nuclear reactors, and drilling rigs) and that subtracted from the total quantity of energy produced from a certain source.

In this framework, an economy that can obtain energy with a higher value of NER, NEG or EROEI can distribute more labor and capital among different activities. Therefore, such an economy has a greater potential for development and growth than another (Fagnart and Germain 2016).

\section{Energy Return Ratio and Relative Indices}

To assess the energy efficiency of RES, several methodologies and relative indices can be used. Some scholars prefer to adopt, for example, energy analysis (EA). This method, introduced by H.T. Odum in 1983, evaluates the integrated relationship between the economic system and its environment. In other words, it considers "total direct and indirect available energy of one kind used to make a product or service, measured in solar emjoules (sej)" (Zhang et al. 2019). The EA calculates some indices, such as: (i) the emergy yield ratio (EYR), which measures the ability of a process to exploit local resources by using economic resources from outside; (ii) the environmental loading ratio (ELR), which quantifies the environmental stress caused by the production system; (iii) and the Energy Sustainability Index (ESI), which measures the potential contribution of a resource or process to the economy per unit of environmental loading (Buonocore et al. 2015).

Although this analysis is important to assess the efficiency of an energy process, the authors focused expressively on net energy analysis, as stressed in the introduction section, for calculating 
the different typologies of energy return ratio. Generally, this choice allows us to obtain more strictly economic evaluations than those of energy analysis.

NEA is a wide set of methods used to determine the efficiency of a process in capturing and converting energy. For this reason, this type of analysis is specifically applicable to energy producing industries. NEA's goal is to calculate whether the energy output supplied by a production system, surpasses the energy input required to build, operate and maintain the infrastructure (Palmer and Floyd 2017). Moreover, it is necessary to take into account the quantity of energy to extract the energy resources and convert them, etc. (Evans 1982). In fact, the cumulative quantity of commercial energy (i.e., renewable, nuclear or fossil), invested to extract, produce and manufacture a product and to transport it to its point of use (embodied energy), can be converted only in a portion of useful energy (or exergy). This is because a certain amount of energy will be unavoidably lost as entropy effects and technological inefficiency (or anergy) of the process (Liao et al. 2015).

NEA is often useful for calculating the ERR of an energy source, which compares the amount of energy consumed in the production process and the amount of energy suitable for societal use. This assessment is similar to the embodied exergy analysis, which consists of calculating how much useful energy is lost and embodied in a product; additionally, it quantifies the emission and waste amount, caused by energy depreciation, allocated either to producers or to consumers (Liao et al. 2015). For instance, while a photovoltaic (PV) cell has a well-defined conversion efficiency (e.g., MJ electricity/MJ solar radiation), the energy efficiency of its entire supply chain and electricity distribution needs to be calculated using an ERR (Brandt and Dale 2011).

Over the years, several ERR typologies have been proposed, such as NER, NEG, and EROEI, which assess both the quality of an energy source and the sustainability of processes to harness it.

According to Spath and Mann (2000), NER can be defined as:

$$
\mathrm{NER}=\mathrm{Eg} / \mathrm{Eff}
$$

where NER is the net energy ratio of a defined energy source (such as electricity, fuels, etc.); Eg is the energy gained from an energy source (output) (i.e., electric energy delivered by the utility grid) and expressed in Joules or kWh; Eff is the energy consumed within the energy production system (input) and expressed in Joules or kWh. NER is dimensionless, and to assess energy source efficiency, it should reveal a value greater than one.

NEG refers to the difference between the energy consumed to produce an energy source and the quantity of energy gained from that production (Rahimi et al. 2018). NEG is equal to:

$$
\text { NEG = energy content output }- \text { net energy input }
$$

where NEG is the net energy gain (Joules or $\mathrm{kWh}$ ); energy content output is the total energy (gross) gained and corresponds to the term Eg in Equation (1) (expressed in Joules or kWh); net energy input is the total (gross) energy consumed and corresponds to the term Eff in Equation (1) (expressed in Joules or kWh). Clearly, a NEG is achieved when the value is positive.

EROEI is the ratio of the amount of energy gathered from a source and the energy consumed directly or indirectly by the process (Fagnart and Germain 2016) and is equal to:

$$
\text { EROEI }=(\text { total energy output }) /(\text { total energy input })
$$

where EROEI is the energy return on energy investment; total energy output is the energy left over after an energy source is produced (expressed in Joules or kcal); total energy input is all energy required to produce an energy source (expressed in Joules or kcal). As the numerator and denominator are generally expressed in the same units, the index is dimensionless. To measure the energy efficiency of a fuel, EROEI should be a ratio of at least up to 5:1 for non-renewable energy sources and 3:1 for renewable sources (Murphy et al. 2011). When comparing Equations (1) and (2), EROEI and NER seem to be similar. 
This is true, but the lack of a standardization method prevents a comparison between these indices (Brandt and Dale 2011). In fact, Fagnart and Germain (2016) consider these indices different, as EROEI assesses only the input and output energy of the main process, while NER also considers intermediary consumption energy flows. Consequently, the latter is more detailed than the former.

Moreover, Hall et al. (2014) recognize the following four typologies of EROEIs depending on system boundary: (1) standard (EROIST); (2) point of use (EROIPOU); (3) extended (EROIEXT); (4) societal (EROISOC).

The first approach considers all energy outputs (direct and indirect) and all energy inputs without considering labor and financial services. Moreover, if EROIST is applied to a fuel, the assessment of energy output includes all energy consumption from production to the firm gate. For instance, EROIST takes into account, for the production phase, the energy consumption for oil extraction, but the agricultural phase for biodiesel.

Conversely, EROIPOU considers a system boundary more expanded than the previous one because it involves energy inputs associated with refining and transporting a fuel. Thus, for biofuel production, all phases of transformation in fuels are evaluated; for instance, with biodiesel, agricultural, oil extraction and trans-esterification ones are evaluated, while for ethanol, agricultural phase, sugar extraction, and distillation ones are evaluated.

In EROIEXT, the system boundary is further expanded to include the energy required to obtain and transport a fuel to the point of use (i.e., oil or diesel pump).

Finally, EROISOC differs from the others, as it considers the numerator the sum of the energy content of all fuels delivered to a city, region, or nation and the denominator the total energy consumed to get those fuels.

To calculate the ERR, in the beginning, both direct and indirect (embodied) energy requirements for producing an energy source were considered. This method is derived from engineering process modeling and follows a bottom-up approach, where all energy inputs of the main production phase are considered (Lenzen and Munksgaard 2002). Subsequently, this procedure was standardized by life cycle assessment (LCA), a methodology regulated by ISO 14040 (ISO 2006a) and ISO 14044 (ISO 2006b) that analyses environmental impacts of a product from resource extraction (cradle) to processing to disposal (grave). When an LCA study focuses only on energy aspects, it is often called an energy life cycle assessment (ELCA), which consists of an energy balance accounting for energy used in the production process and compares it to the amount of energy contained in the resulting energy sources (Pradhan et al. 2008). For instance, to assess the EER of the electricity produced in a PV plant, it must be considered as the unit of energy obtained (e.g., $1 \mathrm{kWh}$ ) and the total energy consumed over the lifetime of the device (e.g., 20 years). The latter refers to energy necessary for: constructing and decommissioning the plant, extracting and transporting silicon and other materials, producing the cell, transportation of materials, etc.

In the Figure 1, the relationship and hierarchical structure of the abovementioned indices are reported.

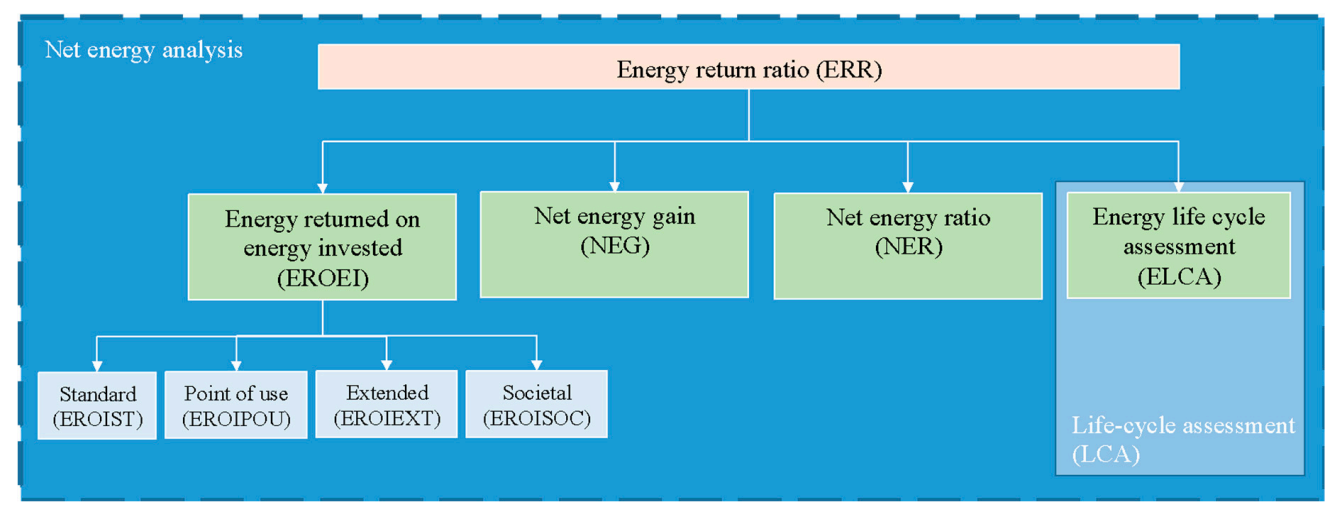

Figure 1. The hierarchical structure and the relationship among the considered energy efficiency indices. Source: own elaboration. 


\section{Literature Review}

It was very difficult to find some general reviews on the ERR linked to renewable energy resources, such as biomass, solar and wind energy. This was due to the very extensive field of the considered study and, above all, because scholars preferred mostly to carry out a systematic review or meta-analysis on a specific RES, comparing, where possible, the same energy efficiency index. Thus, according to this premise, the authors aimed to analyze mainly the direction taken by the research into the energy efficiency of RES, highlighting both the prior state of the art and recent trends in the academic literature. Nevertheless, in the following section, some (mostly representative) examples of reviews have been reported. Only a few of them, as mentioned, focus properly on the aim of this study; the other ones, though equally important, focus only on the energy efficiency of specific RES.

For instance, Murphy et al. (2016) analyzed the inconsistencies common within the NEA literature, and in the assessment of energy return ratio and its typologies. Indeed, though it is important to have a broad measure of energy profitability, "comparisons, among indices, are often misleading, particularly if the units being compared are different". Consequently, the authors proposed, as a possible solution, the application of the LCA methodology within the NEA community.

Walmsley et al. (2018) "collected energy assessment data for the most common electricity generation methods and evaluates five Energy Ratios", i.e., EROI (standard and external), Energy Payback Time (EPT), Primary Energy Factor (PEF), and Resource Utilization Factor (RUF). Thus, the authors compared the values of both fossil fuels and renewables sources. They showed that EROIs correspond to short Energy Payback Times and vice versa and that "Energy Ratio performance levels for renewable energy generation sources-hydro, wind, geothermal and solar-heavily rely on the quality of the primary natural resource available". The authors recommended EROI (external) and Resource Utilization Factor as the most useful metrics for inclusion in full sustainability assessment.

Capellán-Pérez et al. (2019) applied a new methodology to "assess the energy and material investments required in the next decades to achieve the transition from fossil fuels to renewable energy sources in the electricity sector". They considered a number of novel methodological contributions in relation to the state of the art of energy systems and EROI analysis, for resolving some of the existing differences in the literature. The indices, identified in the literature, showed levels well below the thresholds needed to sustain industrial complex societies, making questionable the transition towards a totally green electricity sector.

Fabre (2019) tried to "estimate future EROIs in a decarbonized electricity system by examining a broad range of scenarios". These scenarios were given by the several estimations of EROIs made in literature, derived from diverse data sets and methodologies, of which none was authoritative. The author arrived at the same conclusion as Capellán-Pérez et al. (2019)—renewable electricity is not as energetically efficient as previously thought. However, the choice to undertake a renewable transition-or not-has to take into account not only EROI indices but also the negative externalities and the scarcity of fossil fuels.

Moving towards reviews on EE indices applied to a specific RES, many of them are related to energy from biomass, followed by solar-PV and, lastly, by wind.

Regarding the latter, an initial study was carried out by Lenzen and Munksgaard (2002). They reported results in terms of energy intensity, stressing that the existing life cycle assessments of energy and $\mathrm{CO}_{2}$ intensity for wind turbines showed considerable variations due to "discrepancies in the energy contents of materials and the analyses' methodology and scope". To minimize this issue, they proposed to use a standardized methodology, and input-output-based hybrid techniques.

Kubiszewski et al. (2010) published a meta-analysis of EROIs based on a survey of wind turbine literature, ranging in date from 1977 to 2007 and adding almost 50 more studies to the publication of Lenzen and Munksgaard (2002). They evaluated only operational studies with a power rating for turbines less than 1 MegaWatt (MW). They concluded that even if "wind energy could yield significant economic and social benefits relative to other power generation systems" ... "technical progress and a 
high EROI are not sufficient conditions for the continued rapid expansion of wind energy. A number of social, economic, environmental and regulatory issues need resolution".

Price and Kendall (2012) stressed, two years after, that the conclusion of Kubiszewski et al. (2010) lacked sufficient data or used unreliable data, highlighting a lack of transparency in reporting modeling inputs and outputs. Thus, they stated that "it is necessary to establish clear methods for assessing transparency and to develop conventions for LCA reporting that promote future comparisons". Thus, they identified guidelines for evaluating reporting transparency, that predict the necessities of meta-analyses of LCA applied to renewable energy technologies.

Regarding reviews on solar PV, Hernandez and Kenny (2012) published the first important paper in 2012. The authors assessed the methods for calculating and measuring the energy performance of Domestic Solar Water Heating, considering the existing studies on life cycle, embodied energy and 'net energy' performance. They revealed: "that while there is a real potential for life cycle energy savings through domestic solar water heating installations, devising mechanisms to ensure proper design, installation and operation of systems is essential for this technology".

Bhandari et al. (2015) carried out, instead, a systematic review and a meta-analysis of the embedded energy, energy payback time (EPBT), and EROI metrics of PV technologies, published in 2000-2013. They stated that "Across different types of PV, the variation in embedded energy was greater than the variation in efficiency and performance ratio suggesting that the relative ranking of the EPBT of different PV technology today and in the future depends primarily on their embedded energy and not their efficiency".

Good (2016) presented an evaluation of the published results relative to life cycle assessments of different hybrid photovoltaic-thermal (PV/T or PVT) concepts and installations, aiming to find a common ground. The author stated that "payback time for both energy and greenhouse gas emissions of the PV/T systems are much shorter than their expected lifetime. However, due to the use of different methods and unclear data sources, it is difficult to make any wide-ranging conclusions about the environmental impact of PV/T modules".

Al-Waeli et al. (2017) reviewed various aspects (such as performance parameters and efficiencies) of PV/T systems through the existing literature, aiming to highlight the key points in this field and show the different techniques used for such systems. They did also a critical review of many findings of previously conducted research. They concluded: "the PV/T air heater system is promising for future preheating air applications. Furthermore, the PV side views require more attention in technical and cost terms. However, more research is essential to reduce the cost and, improve the effectiveness and technical design of such systems".

Koppelaar (2017) analyzed twenty-nine studies on mono- and polysilicon solar-photovoltaic (PV) modules, providing an Energy Payback Time (EPT) or NER value and examining the influence of data age, system boundaries, and technological configurations. Considering the different problems in comparing several studies, the author recommended: "in future studies to use recent data reflecting up-to-date technological standards and include the collection year of any used datasets. And to strictly follow existing ISO14040, ISO14044, and IEA-PVPS T12 standards, especially by transparent reporting of: solar module specifications, energy inputs for individual facilities and non-module components, technology assumptions, and electric/thermal conversions".

Palmer and Floyd (2017) reviewed the differing approaches of NEA as relevant tools for assessing the role of PV in future energy systems and considering the EROI and energy payback time (EPBT). They discovered that there were many apparent divergences between studies due the different goal definitions. Thus, it is important to consider EROI or EPBT "with specific reference to the details of the particular study context, and the research questions that it seeks to address. NEA findings in a particular context cannot definitively support general statements about EROI or EPBT of PV electricity in all contexts".

The last part of this section focused on reviews about energy obtained from biomass. A first paper was published by Pradhan et al. (2008) and investigated models used to calculate the net energy 
ratio (NER) of biodiesel production. The aim was to indicate the reasons for the opposing results deriving from several studies done on this supply chain. The authors discovered that "the most significant factors in altering the results were the proportions of energy allocated between biodiesel and its co-products. The lack of consistency in defining system boundaries has apparently led to very different results". Consequently, they proposed a unified model for biodiesel energy analysis to answer the renewability question because, often, the same definitions of NER used among the models were different.

Milazzo et al. (2013) reviewed the performance and prospects of rape biodiesel production on a global basis using some 40 life cycle assessments, identifying best (agricultural) practice and laggards. In their concluding remarks, the authors stressed that: "Opportunities to improve rape biodiesel life cycle energy efficiency and environmental impact by implementing new technologies in agriculture as well as in industrial processing have been identified for various Brassica oil crop cultivars in relevant production areas. The consequences of large-scale renewable energy action plans have been considered. Improvements are needed for rape biodiesel to stay in business".

Rocha et al. (2014) assessed and compared, by meta-analysis with previous published studies, the main environmental life cycle impacts and energy balance (NER) of ethanol, from sugarcane, and biodiesel from soybean and palm oil. The authors concluded: "the choices of co-products allocation method, transport distance and inventory database of the country have significant influence on the results of the life cycle environmental performance of biofuels".

Arodudu et al. (2017a) studied tools, methodologies and frameworks that can be adopted individually or together with each other for bridging the methodological gaps in application to agro-bioenergy systems. They argued that using "energy return on energy invested-EROEI, human appropriation of net primary production-HANPP, net greenhouse gas or carbon balance-NCB, water footprint individually and in combination with each other will also lead to further derivation of indicators suitable for assessing relevant environmental, social and economic impact categories".

Carneiro et al. (2017) aimed to identify global tendencies based on a statistic and critical interpretation of previously published study results, reviewing 61 recent papers addressing the environmental evaluation of microalgae biofuels. They considered, among other elements, Energy Ratio (ER) allowing a broad estimation of the net energy efficiency of biofuels. The authors stated: "in terms of energy efficiency, algae biofuels cannot compete with other biofuels or fossil fuels. They present very low performances, even demanding more energy for its production then the energy they can deliver. Energetic and GWP performances can be improved if production pathways are carefully chosen and optimized".

Ketzer et al. (2018) developed a comparative meta-analysis of 16 recent LCA studies on algal bioenergy production pathways, calculating the energy return on investment (EROI) for each study. Of course, also in this review, large variations for the EROI were underlined. This depended "on the assumptions made on biomass productivity, lipid content, required energy, and the output of the system, the energetic performance was assessed".

Ribeiro et al. (2018) presented new information regarding the conventional torrefaction process, as well as analyzing the literature and studies of the innovative techniques that have been in development for the improvement of torrefied biomass qualities. They argued that "the publications regarding this topic have been strongly increasing, which suggests a strong academic and industrial interest for this subject in the last few years". They stressed the importance of the torrefaction parameters on the final properties of torrefied biomass, as well as the importance of reactor scales for the definition of ideal protocols.

Considering this literature Considering this literature review, it is evident that, in each paper published in recent years, emerge discrepancies resulting in difficulties to compare them even if come from the same field of research. Most of the reviews stressed the importance of developing guidelines, including, for instance, a common methodology such as LCA to overcome this issue and to measure more properly the energy efficiency of RES. 


\section{Methodology}

In this paper, a qualitative analysis has been used to develop an in-depth and comprehensive summary of the academic literature on the ERR indices related to energy from wind, solar and biomass. Data came from the scientific literature generated through a combination of: (a) database searches (cross-discipline platform of Elsevier and Clarivate) as of March 2020, and (b) screening references of studies retrieved under (a). The aim was to select studies highly referenced to identify, underline, and assess all data related to the abovementioned subject. For an initial selection, the keywords used for the research were: (i) EROEI or EROI; (ii) NEG or NEV); (iii) and NER. For each, the term "renewable" was added. Publications were chosen if they included, as a minimum, the calculation of one of these indices. The authors decided to not limit the search to a specific timespan.

The total number of energy efficiency scientific papers was 162. Six were related to wind, 31 concerned solar, and 125 regarded biomass energy. The first paper was published in 1998, and the most recent studies were published in 2020, covering more than a 20-year interval. Since 2009, the quantity of studies has significantly increased with an average of 15 papers per year, but there was a considerable reduction in the last years (Figures 2 and 3).

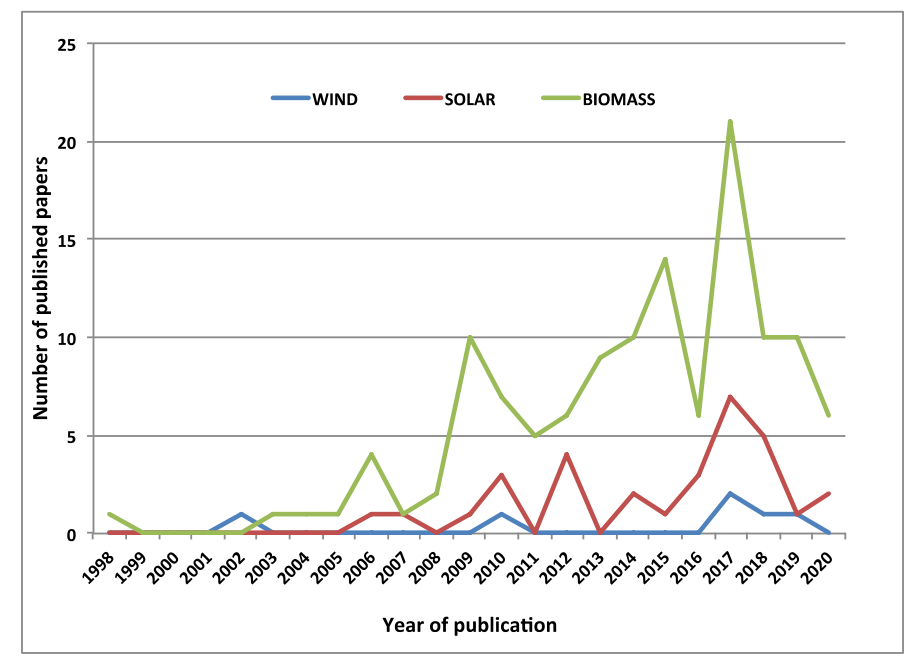

Figure 2. Total collected references per year of publication. Source: own elaboration.

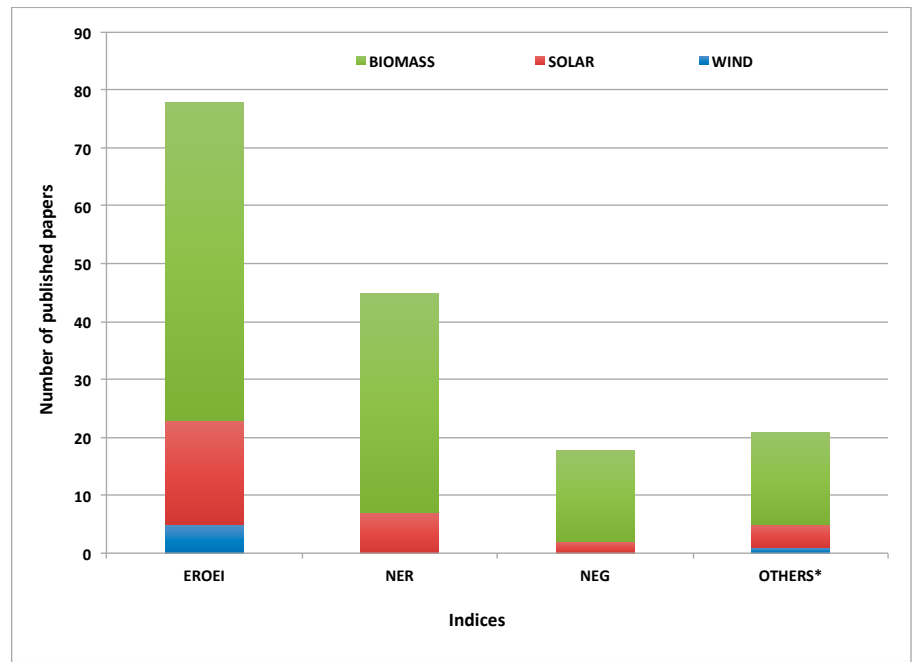

Figure 3. Total collected references per energy source and index. Source: own elaboration. Others*: papers including more general measures such as net energy, energy efficiency and energy balance. 
Figure 3 shows that the most calculated index is the EROEI (78), followedby NER (45), others (21), and NEG (18), because it provides powerful insights into the real balance sheets that drive our "petroleum economy" over the transition to lower carbon energy sources (Hall and Klitgaard 2012; Rye and Jackson 2018).

According to Brockway et al. (2019), numerous aspects have affected the increasing attention that has been paid to the study of EROEI, for example: (i) the decrease in EROEI ratios of fossil fuels due to the depletion of finite resources, the leading energy source up to at least 2050; (ii) the fact that the EROEI ratios for RES are often controversial, since they can change according to the adopted methodology, and are commonly lower than fossil fuels. Thus, it must be considered that renewable-led energy transition has unfavorable socio-economic impacts.

Capellán-Pérez et al. (2019) underlined that many studies have been carried out to estimate the EROEI of individual RES technologies (as the authors have already shown in Figures 2 and 3) and important differences exist depending on the technology, system design and location, and the field is plagued with methodological differences related to the functional units (e.g., an MJ of heat energy versus an MJ of grid electricity) or the boundaries of the analysis (i.e., mine mouth vs. end use or energy technology vs. energy system) (Price and Kendall 2012; Weißbach et al. 2013; De Castro et al. 2014; Raugei et al. 2015; Ferroni and Hopkirk 2016; Murphy et al. 2011; Hall 2017; De Castro and Capellán-Pérez 2018).

\section{Results and Discussion}

The authors decided to limit the discussion to only EROEI/EROI, according to the abovementioned premise, choosing among those studies ones that were more similar and thus more easily comparable. Thus, a final number of 30 main studies were taken into account (Table 1).

The analysis showed that, in general, all renewable energy sources present a good level of energy efficiency, even though it was impossible to compare all values calculated in the various studies. Indeed, as already stressed in Section 3, there are different energy conversion technologies, raw materials, and system boundaries that, without a standardization method, do not permit accurate assessment.

Table 1. Renewable energy sources and energy return on energy invested EROEI values.

\begin{tabular}{|c|c|c|c|}
\hline RES & Typology & Values & Reference \\
\hline \multirow{2}{*}{ WIND } & Inshore & $34-58$ & \multirow{2}{*}{$\begin{array}{l}\text { (Kubiszewski et al. 2010; Walmsley et al. 2017; } \\
\text { Huang et al. 2017; Dupont et al. 2018) }\end{array}$} \\
\hline & Offshore & $16.7-17.7$ & \\
\hline SOLAR & Photovoltaic & $5-34$ & $\begin{array}{l}\text { (Ng and Mithraratne 2014; Bhandari et al. 2015; } \\
\text { Pickard 2017; Raugei et al. 2017; } \\
\text { Zhou and Carbajales-Dale 2018; } \\
\text { Liu and Van den Bergh 2020; Goel et al. 2020) }\end{array}$ \\
\hline \multirow{9}{*}{ BIOMASS } & $\begin{array}{l}\text { Sugarcane and stems } \\
\text { gasification }+ \text { organic waste }\end{array}$ & 8 & (Preston and Rodríguez 2009) \\
\hline & Bio-crude from algae & $<1$ & (Beal et al. 2012) \\
\hline & $\begin{array}{l}\text { Synthetic natural gas (SNG) } \\
\text { from microalgae }\end{array}$ & $0.08-1.84$ & (Brandenberger et al. 2013 ) \\
\hline & $\begin{array}{l}\text { Biodiesel from Linum } \\
\text { usitatissimum, Camelina sativa } \\
\text { and Brassica }\end{array}$ & $>1$ & (Restuccia et al. 2013) \\
\hline & Biogas from roadside vegetation & $2.17-2.88$ & (Meyer et al. 2014) \\
\hline & Heat from industrial hemp & 12.6 & (Kolarikova et al. 2014) \\
\hline & Biodiesel from rapeseed & $1.73-2.60$ & (Firrisa et al. 2014) \\
\hline & Biodiesel from rapeseed & $<2.2$ & (Van Duren et al. 2015) \\
\hline & Biogas from grass & $1.7-3.3$ & (Meyer et al. 2015) \\
\hline
\end{tabular}


Table 1. Cont.

\begin{tabular}{|c|c|c|c|}
\hline RES & Typology & Values & Reference \\
\hline \multirow{28}{*}{ BIOMASS } & Biodiesel from rapeseed & 1.1 & \multirow{8}{*}{ (Uusitalo et al. 2017) } \\
\hline & Grass methane & 2.5 & \\
\hline & Ethanol from barley & 0.9 & \\
\hline & Ethanol from oat & 0.9 & \\
\hline & Ethanol from wheat & 0.9 & \\
\hline & Synthetic natural gas from wood & 2.9 & \\
\hline & $\begin{array}{l}\text { Synthetic natural gas } \\
\text { from willow }\end{array}$ & 2.9 & \\
\hline & Ethanol from straw & 2.0 & \\
\hline & $\begin{array}{l}\text { Ethanol from corn } \\
\text { (low intensity agriculture) }\end{array}$ & $5.4-5.9$ & \multirow{4}{*}{ (Arodudu et al. 2017b) } \\
\hline & $\begin{array}{c}\text { Biogas from corn } \\
\text { (low intensity agriculture) }\end{array}$ & $14.7-22.4$ & \\
\hline & $\begin{array}{c}\text { Ethanol from corn } \\
\text { (high intensity agriculture) }\end{array}$ & $1.2-1.7$ & \\
\hline & $\begin{array}{c}\text { Biogas from corn } \\
\text { (high intensity agriculture) }\end{array}$ & $2.2-10.2$ & \\
\hline & Biodiesel from Ricinus communis & 2.60 & (Amouri et al. 2017) \\
\hline & Ethanol from corn & $1.01-1.07$ & (Murphy et al. 2016) \\
\hline & Ethanol from corn & 0.67 & \multirow{5}{*}{ (Wang and Cheng 2018) } \\
\hline & Ethanol from cassava & 1.15 & \\
\hline & Ethanol from sweet sorghum & 0.48 & \\
\hline & Ethanol from corn stover & $1.26-1.56$ & \\
\hline & Ethanol from corncob & $1.25-1.42$ & \\
\hline & Biogas from microalgae & $2.3-5$ & \multirow{2}{*}{ (Barbera et al. 2018) } \\
\hline & Lipid-rich solid fraction & $0.8-2.4$ & \\
\hline & $\begin{array}{c}\text { Renewable fuel from woody } \\
\text { biomass residue, such as: } \\
\text { Gasoline } \\
\text { Diesel }\end{array}$ & $\begin{array}{l}4.19 \\
4.31\end{array}$ & (Zupko 2019) \\
\hline & Biofuel from food waste & 2 & \multirow{4}{*}{ (Yeo et al. 2019) } \\
\hline & $\begin{array}{l}\text { Energy and heat from } \\
\text { food waste }\end{array}$ & 2 & \\
\hline & Biogas from food waste & 6 & \\
\hline & $\begin{array}{l}\text { Energy, heat and biogas from } \\
\text { food waste }\end{array}$ & 8 & \\
\hline & $\begin{array}{l}\text { Combined production of heat } \\
\text { and power from Napier grass }\end{array}$ & 5.0 & (Manouchehrinejad et al. 2020) \\
\hline & $\begin{array}{l}\text { Bioethanol from different spring } \\
\text { triticale cultivation systems }\end{array}$ & $\begin{array}{c}\text { Average } \\
\text { value } 1.114\end{array}$ & (Klikocka et al. 2019) \\
\hline
\end{tabular}

Table 1 showed that wind energy presents the highest EROEIs when considering models and conceptual installations, although results were slightly lower when considering operational installations. For instance, in New Zealand, EROEIs were about 34 with peaks of about 58 over a lifespan of 20 years, whereas offshore installations had values equal to 16.7-17.7 depending on the presence of a substation (Kubiszewski et al. 2010; Walmsley et al. 2017; Huang et al. 2017; Dupont et al. 2018). 
The EROEIs of PV farms have been revisited and computed in Switzerland, with values ranging from seven to 10 according to the different system boundaries considered (Raugei et al. 2017). PV installations showed EROEIs ranging widely according to the used technology (semi-transparent building-integrated PV, thin film technologies of crystalline silicon, etc.) and locations (insulations) from five5 to 34 (Ng and Mithraratne 2014; Bhandari et al. 2015; Pickard 2017; Zhou and Carbajales-Dale 2018; Liu and Van den Bergh 2020). Goel et al. (2020) focused on two different PV systems (standalone and grid-connected systems) showing an EROEI equal to 5.42 and 6.62, respectively. However, even if the EROEI value increases, it is unthinkable to power the European electrical system using renewable energies. In fact, Dupont and Jeanmart (2019), who have assessed the potential electricity production from wind and solar power in the European Union, affirm that, considering the current EROEI values, it is impossible to supply the electricity required in Europe using only these technologies because it is necessary to increase energy storage systems. This implies the decrease in EROI value and, consequently, a reduction in electricity efficiency.

With regards to biomass, the variability of the results were greater than wind and solar energy due to the high number of available conversion technologies (thermochemical, biological, and chemical-physical) and of several types of feedstock (dedicated crops, animal and vegetal residual biomass, marine biomass) for obtaining biofuels and bioenergy. This is also the reason why there are many more studies published in this research field.

Consequently, it was very difficult to compare all the different EROEI results. Even if they considered the same technologies and feedstock, they also varied in some way. Thus, the authors decided to divide in three main categories the EROEI scores: below one; from one to five; over five.

In the first ranking, there is the production of ethanol, from any kind of grain (oat, wheat, barley, corn and sweet sorghum) in papers published in recent years, as well as bio-crude oil and synthetic natural gas (SNG) from micro-algae (Beal et al. 2012; Brandenberger et al. 2013; Uusitalo et al. 2017; Wang and Cheng 2018). In the second, some efficiency values often slightly exceeded the threshold of the unit, especially from biodiesel from rapeseed and ricinum (Restuccia et al. 2013; Firrisa et al. 2014; Van Duren et al. 2015; Amouri et al. 2017; Uusitalo et al. 2017) and ethanol from corn stover, corncorb, cassava (Manihot esculenta C.), corn (high intensity agriculture) and straw (Arodudu et al. 2017b; Murphy et al. 2016; Uusitalo et al. 2017; Wang and Cheng 2018). However, the EROEI value also depends on the technology used to produce a biofuel. For instance, a study on ethanol from spring triticale cultivated with traditional systems reduced tillage technology and nitrogen fertilization, showing EROEI values equal to 1.138, 1.089 and 1.114 respectively (Klikocka et al. 2019). Moreover, the typologies of considered systems, as well as the various obtained energies, could lead to different results. For instance, Yeo et al. (2019) proposed Smart Food Waste Recycling Bin (S-FRB) technology to produce three different typologies of energy (i.e., biofuel, electricity and heat, biogas) from food waste and wood chips in four different scenarios. The study found that producing biogas or, simultaneously, electricity, heat and biogas, obtained high values of EROEI, i.e., six and eight, respectively. On the contrary, biofuel and electricity/heat had an energy efficiency index equal to two. It is more favorable the production of biogas from grass, wood, willow, roadside vegetation, and microalgae (Meyer et al. 2014; Meyer et al. 2015; Uusitalo et al. 2017; Barbera et al. 2018). In the last category, the score fluctuates significantly from 5.9 for ethanol from corn to 22.4 for biogas from the same crop, both with the application of a low intensity agriculture system, characterized by a small quantity of energy inputs like fertilizers, fossil fuels, and pesticides (Arodudu et al. 2017a). Interesting results are also shown by the performance of the use of sugarcane (Saccharum officinarum L.) and stems, together with organic waste, equal to eight (Preston and Rodríguez 2009), and combustion in the heating of industrial hemp, equal to 12.6 (Kolarikova et al. 2014). Finally, the work of Zupko (2019) differs from the aforementioned categories because it assessed the EROI of renewable gasoline and diesel produced from woody biomass residues using integrated hydropyrolysis and hydroconversion technology. The study showed an energy index equal to 4.19 and 4.31 per kilogram of diesel and gasoline, respectively. 
In this context, the research findings highlight that, since 2011, there has been a tendency to consider, apart from EROEI or EROI, some sustainable indices such as carbon footprint (CF) (Zupko 2019; Manouchehrinejad et al. 2020; Roles et al. 2020), energy payback time (EPBT) (Perez et al. 2011; Bhandari et al. 2015; Koppelaar 2017; Pickard 2017; Walmsley et al. 2018; Gómez-Camacho and Ruggeri 2019; Goel et al. 2020), energy return on carbon invested (EROC) (Liu and Van den Bergh 2020), energy sustainability analysis (ESA) (Gómez-Camacho and Ruggeri 2019) or carbon-equivalent payback time (CPBT) (Perez et al. 2011). In fact, 26 documents consider these indices connected with EROEI values, indicating an increasing interest towards both energy efficiency and sustainable aspects of RES.

Though not reported in Table 1, some interesting considerations could be made regarding the NER index. In the case of biomass, for instance, this varies from 1.09 to 1.19 for the production of ethanol from grains (Dong et al. 2008), while it reaches higher levels, from 3.14 to 9.3, if it is made from sugarcane or cassava (Dias De Oliveira et al. 2005; Macedo et al. 2008; Hanif et al. 2017). The most efficient process is that of the gasification of willow with an NER equal to 13.3 (Heller et al. 2008), while diesel from palm oil (Elaeis guineensis J.) has the same range of ethanol production (3.58) (Pleanjai and Gheewala 2009). These results are almost similar to those of the EROEI values calculated for the same biofuels.

In this context, some final considerations can be made: there is no evident evolution of EROEI increment over time according to the papers collected in this review. It is likely that this is due to the fact that the year of publication does not always correspond with the conducted study. Obviously, only the advancement of technology can improve the level of EE of RES and not an increase in biomass yield. Some technologies, like anaerobic digestion and combustion, are already mature and so the final EROEI score generally presents higher values.

Finally, the EE values can increase if the calculation takes into account the energy content of byproducts of the supply chain. For instance, in the case of biodiesel from microalgae or soybean, the inclusion of the calorific value of glycerine and flour resulting from the extraction of oil increased the energy indices (Rana et al. 2013; Piastrellini et al. 2017).

\section{Conclusions}

Energy production from RES may be more widespread and less expensive in a scenario with high energy efficiency and could support the transition towards decarbonizing the global energy system. Therefore, policymakers should consider any visions of a rapid, reliable, and low-cost transition to whole energy systems completely based on these alternative eco-friendly sources.

Our analysis showed that the trend is characterized by many studies relating to biomass because it is the renewable source with a wide range of raw materials and conversion technologies. It is also highlighted that the references have decreased in the last two years, after a peak in 2017 and an average increase of 15 papers per year. The reduction is probably due to the lack of industrial applications of advanced technologies.

The analysis showed that all RES generally have an acceptable level of energy efficiency, in terms of ERR, even with peculiar differences among sources. In particular, solar and wind energy, although they display possible room for improvement, have reached mature and advanced levels of technology, unlike biomass. Biomass energy can be used to produce almost all energy carriers, and its efficiency depends on the large variety of biomass feedstock, different energy extraction and conversion methods, and the manner in which the biomass is produced and collected. Thus, it can be considered as a versatile RES that is able to bridge the energy supply and demand gap in different energy applications such as electricity, transport, and buildings (Tareen et al. 2018). However, according to the analyzed research, bioenergy and biofuels seem to be much more expensive and less efficient than equivalent fossil-based energy. This is due to their lower density, higher moisture content, and hydrophilic nature, which causes their heating value to decrease, making it difficult to use biomass for large-scale productions (Ribeiro et al. 2018). Consequently, it is important to overcome these issues in improving the energy efficiency in order to allow energy from biomass to play an important role in future energy models. 
In this direction, Moriarty and Honnery (2019) suggested, for example, the introduction of a green EROIfor measuring the global net energy, produced in an ecologically sustainable manner. Many scholars, indeed, believe that it is necessary to consider, along with EROEI value, sustainable indices, such as CF, EROC and ESA.

Policymakers should take into consideration all of this evidence for redefining their policies and strategies to foster the large-scale replacement of fossil fuels with RES in the energy system.

Author Contributions: All the authors contributed equally and substantially to the realization of the paper. All authors have read and agreed to the published version of the manuscript.

Funding: This research received no external funding.

Conflicts of Interest: The authors declare no conflict of interest.

\section{References and Notes}

Al-Waeli, Ali HA, Kamaruzzaman Sopian, Hussein A. Kazem, and Miqdam T. Chaichan. 2017. Photovoltaic/Thermal (PV/T) systems: Status and future prospects. Renewable and Sustainable Energy Reviews 77: 109-30. [CrossRef]

Amouri, Mohammed, Faroudja Mohellebi, Toudert Ahmed Zaïd, and Majda Aziza. 2017. Sustainability Assessment of Ricinus Communis Biodiesel Using LCA Approach. Clean Technologies and Environmental Policy 19: 749-60. [CrossRef]

Arodudu, Oludunsin, Katharina Helming, Hubert Wiggering, and Alexey Voinov. 2017a. Towards a More Holistic Sustainability Assessment Framework for Agro-Bioenergy Systems-A Review. Environmental Impact Assessment Review 62: 61-75. [CrossRef]

Arodudu, Oludunsin, Katharina Helming, Hubert Wiggering, and Alexey Voinov. 2017b. Bioenergy from Low-Intensity Agricultural Systems: An Energy Efficiency Analysis. Energies 10: 29. [CrossRef]

Barbera, Elena, Eleonora Sforza, Vincenzo Musolino, Sandeep Kumar, and Alberto Bertucco. 2018. Nutrient recycling in large-scale microalgal production: Mass and energy analysis of two recovery strategies by process simulation. Chemical Engineering Research and Design 132: 785-94. [CrossRef]

Beal, Colin M., Robert E. Hebner, Michael E. Webber, Rodney S. Ruoff, and A. Frank Seibert. 2012. The energy return on investment for algal biocrude: Results for a research production facility. BioEnergy Research 5: 341-62. [CrossRef]

Bhandari, Khagendra P., Jennifer M. Collier, Randy J. Ellingson, and Defne S. Apul. 2015. Energy payback time (EPBT) and energy return on energy invested (EROI) of solar photovoltaic systems: A systematic review and meta-analysis. Renewable and Sustainable Energy Reviews 47: 133-14. [CrossRef]

Brandenberger, Martin, J. Matzenberger, Franz Vogel, and Ch Ludwig. 2013. Producing synthetic natural gas from microalgae via supercritical water gasification: A techno-economic sensitivity analysis. Biomass and Bioenergy 51: 26-34. [CrossRef]

Brandt, Adam R., and Michael Dale. 2011. A General Mathematical Framework for Calculating Systems-Scale Efficiency of Energy Extraction and Conversion: Energy Return on Investment (EROI) and Other Energy Return Ratios. Energies 4: 1211-45. [CrossRef]

British Petroleum (BP). 2019. BP Statistical Review of World Energy, 68th edition. June 2019. Available online: https://www.bp.com/content/dam/bp/business-sites/en/global/corporate/pdfs/energy-economics/ statistical-review/bp-stats-review-2019-full-report.pdf (accessed on 5 March 2019).

Brockway, Paul E., Anne Owen, Lina I. Brand-Correa, and Lukas Hardt. 2019. Estimation of global final stage energy-return-on-investment for fossil fuels with comparison to renewable energy sources. Nature Energy 4: 612. [CrossRef]

Buonocore, Elvira, Laura Vanoli, Alberto Carotenuto, and Sergio Ulgiati. 2015. Integrating life cycle assessment and emergy synthesis for the evaluation of a dry steam geothermal power plant in Italy. Energy 86: 476-87. [CrossRef]

Capellán-Pérez, Iñigo, Carlos de Castro, and Luis Javier Miguel González. 2019. Dynamic Energy Return on Energy Investment (EROI) and material requirements in scenarios of global transition to renewable energies. Energy Strategy Reviews 26: 100399. [CrossRef]

Carneiro, Maria Luisa N. M., Florian Pradelle, Sergio L. Braga, Marcos Sebastião P. Gomes, Ana Rosa FA Martins, Franck Turkovics, and Renata NC Pradelle. 2017. Potential of biofuels from algae: Comparison with 
fossil fuels, ethanol and biodiesel in Europe and Brazil through life cycle assessment (LCA). Renewable and Sustainable Energy Reviews 73: 632-53. [CrossRef]

Chapman, Andrew, Benjamin McLellan, and Tetsuo Tezuka. 2016. Strengthening the Energy Policy Making Process and Sustainability Outcomes in the OECD through Policy Design. 2016. Strengthening the Energy Policy Making Process and Sustainability Outcomes in the OECD through Policy Design. Administrative Sciences 6: 9. [CrossRef]

Clack, Christopher T. M., Staffan A. Qvist, Jay Apt, Morgan Bazilian, Adam R. Brandt, Ken Caldeira, Steven J. Davis, Victor Diakov, Mark A. Handschy, Paul D. H. Hines, and et al. 2017. Evaluation of a proposal for reliable low-cost grid power with $100 \%$ wind, water, and solar. Proceedings of the National Academy of Sciences of the United States of America 114: 6722-27. [CrossRef]

De Castro, Carlos, and Iñigo Capellán-Pérez. 2018. Concentrated Solar Power: Actual Performance and Foreseeable Future in High Penetration Scenarios of Renewable Energies. BioPhysical Economics and Resource Quality 3: 14. [CrossRef]

De Castro, Carlos, Óscar Carpintero, Fernando Frechoso, Margarita Mediavilla, and Luis J. de Miguel. 2014. A top-down approach to assess physical and ecological limits of biofuels. Energy 64: 506-12. [CrossRef]

Dias De Oliveira, Marcelo E., Burton E. Vaughan, and Edward J. Rykiel. 2005. Ethanol as fuel: energy, carbon dioxide balances and ecological footprint. Bioscience 55: 593-602. [CrossRef]

Dong, Xiaobin, Sergio Ulgiati, Maochao Yan, Xinshi Zhang, and Wangsheng Gao. 2008. Energy and eMergy evaluation of bioethanol production from wheat in Henan Province, China. Energy Policy 36: 3882-92. [CrossRef]

Dupont, Elise, Rembrandt Koppelaar, and Hervé Jeanmart. 2018. Global available wind energy with physical and energy return on investment constraints. Applied Energy 209: 322-38. [CrossRef]

Dupont, Elise, and Hervé Jeanmart. 2019. Global Potential of Wind and Solar Energy with Physical and Energy Return on Investment (EROI) Constraints; Application at the European Level (EU 28 Countries). Paper presented at the 32nd International Conference on Efficiency, Cost, Optimization, Simulation and Environmental Impact of Energy Systems, Wroclaw, Poland, June 23-28.

Evans, D. G. 1982. Energy Analysis as an Aid to Public Decision Making. In Institution of Chemical Engineers Symposium Series, Energy: Money, Materials and Engineering. Pergamon: Elsevier, pp. T1-23-T1-36.

Fabre, Adrien. 2019. Evolution of EROIs of electricity until 2050: Estimation and implications on Prices. Ecological Economics 164: 106351. [CrossRef]

Fagnart, Jean-François, and Marc Germain. 2016. Net energy ratio, EROEI and the macroeconomy. Structural Change and Economic Dynamics 37: 121-6. [CrossRef]

Fagnart, Jean-François, Marc Germain, and Benjamin Peeters. 2020. Can the Energy Transition Be Smooth? A General Equilibrium Approach to the EROEI. Sustainability 12: 1176. [CrossRef]

Ferroni, Ferruccio, and Robert J. Hopkirk. 2016. Energy Return on Energy Invested (ERoEI) for photovoltaic solar systems in regions of moderate insolation. Energy Policy 94: 336-44. [CrossRef]

Firrisa, Melese Tesfaye, Iris van Duren, and Alexey Voinov. 2014. Energy efficiency for rapeseed biodiesel production in different farming systems. Energy Efficiency 7: 79-95. [CrossRef]

Goel, Sonali, Bibekananda Jena, and Renu Sharma. 2020. Life Cycle Energy Analysis of a 3.4 kWp Stand-Alone Rooftop Solar Photovoltaic System in Eastern India. Lecture Notes in Civil Engineering 36: 175-83.

Gómez-Camacho, Carlos E., and Bernardo Ruggeri. 2019. Energy Sustainability Analysis (ESA) of Energy-Producing Processes: A Case Study on Distributed H2 Production. Sustainability 11: 4911. [CrossRef]

Good, Clara. 2016. Environmental impact assessments of hybrid photovoltaic-thermal (PV/T) systems-A Review. Renewable and Sustainable Energy Reviews 55: 234-39. [CrossRef]

Hall, Charles A. S. 2017. Will EROI be the primary determinant of our economic future? The view of the natural scientist versus the economist. Joule 1: 635-38. [CrossRef]

Hall, Charles A. S., and K. A. Klitgaard. 2012. Energy and the Wealth of Nations: Understanding the Biophysical Economy. New York: Springer.

Hall, Charles A. S., Jessica G. Lambert, and Stephen B. Balogh. 2014. EROI of different fuels and the implications for society. Energy Policy 64: 141-52. [CrossRef]

Hanif, M., T. M. I. Mahlia, H. B. Aditiya, and Abu Bakar. 2017. Energy and environmental assessments of bioethanol production from Sri Kanji 1 cassava in Malaysia. Biofuel Research Journal-BRJ 4: 537-44. [CrossRef] 
Heinberg, Richard, and Jerry Mander. 2009. Searching for A Miracle: Net Energy Limits $\mathcal{E}$ the Fate of Industrial Society, 4th ed. Washington: Post Carbon Institute Publisher.

Heller, Martin C., Gregory A. Keoleian, Margaret K. Mann, and Timothy A. Volk. 2008. Life cycle energy and environmental benefits of generating electricity from willow biomass. Renewable Energy 29: 1023-42. [CrossRef]

Hernandez, Patxi, and Paul Kenny. 2012. Net energy analysis of domestic solar water heating installations in operation. Renewable and Sustainable Energy Reviews 16: 170-77. [CrossRef]

Huang, Yu-Fong, Xing-Jia Gan, and Pei-Te Chiueh. 2017. Life cycle assessment and net energy analysis of offshore wind power systems. Renewable Energy 102: 98-106. [CrossRef]

Imasiku, Katundu, Valerie Thomas, and Etienne Ntagwirumugara. 2019. Unraveling Green Information Technology Systems as a Global Greenhouse Gas Emission Game-Changer. Administrative Sciences 9: 43. [CrossRef]

ISO (International Organization for Standardization). 2006a. Environmental management-Life cycle assessment-Principles and framework ISO 14040.

ISO (International Organization for Standardization). 2006b. Environmental management-Life cycle assessment-Requirements and guidelines ISO 14044.

Ketzer, Franziska, Johannes Skarka, and Christine Rösch. 2018. Critical Review of Microalgae LCA Studies for Bioenergy Production. BioEnergy Research 11: 95-105. [CrossRef]

Klikocka, Hanna, Armand Kasztelan, Aneta Zakrzewska, Teresa Wyłupek, Bogdan Szostak, and Barbara Skwaryło-Bednarz. 2019. The Energy Efficiency of the Production and Conversion of Spring Triticale Grain into Bioethanol. Agronomy 9: 423. [CrossRef]

Kolarikova, M., Tatiana Ivanova, Bohumil Havrland, and K. Amonov. 2014. Evaluation of sustainability aspect-Energy balance of briquettes made of hemp biomass cultivated in Moldova. Agronomy Research 12: 519-26.

Koppelaar, Rembrandt H. E. M. 2017. Solar-PV energy payback and net energy: Meta-assessment of study quality, reproducibility, and results harmonization. Renewable and Sustainable Energy Reviews 72: 1241-55. [CrossRef]

Kubiszewski, Ida, Cutler J. Cleveland, and Peter K. Endres. 2010. Meta-analysis of net energy return for wind power systems. Renewable Energy 35: 218-25. [CrossRef]

Lenzen, Manfred, and Jesper Munksgaard. 2002. Energy and $\mathrm{CO}_{2}$ life-cycle analyses of wind turbines-Review and applications. Renewable Energy 26: 339-62. [CrossRef]

Liao, Mei, Chao Ma, Dongpu Yao, and Huizheng Liu. 2015. Decomposition of embodied exergy flows in manufactured products and implications for carbon tariff policies. Asia Europe Journal 11: 265-83. [CrossRef]

Liu, Feng, and Jeroen C. J. M. Van den Bergh. 2020. Differences in $\mathrm{CO}_{2}$ emissions of solar PV production among technologies and regions: Application to China, EU and USA. Energy Policy 138: 111234. [CrossRef]

Lyu, Xiaohuan, and Anna Shi. 2018. Research on the Renewable Energy Industry Financing Efficiency Assessment and Mode Selection. Sustainability 10: 222. [CrossRef]

Macedo, Isaias C., Joaquim E. A. Seabra, and João E. A. R. Silva. 2008. Greenhouse gases emissions in the production and use of ethanol from sugarcane in Brazil: the 2005/2006 averages and a prediction for 2020. Biomass Bioenergy 32: 582-95. [CrossRef]

Manouchehrinejad, Maryam, Kamalakanta Sahoo, Nalladurai Kaliyan, Hari Singh, and Sudhagar Mani. 2020. Economic and environmental impact assessments of a stand-alone napier grass-fired combined heat and power generation system in the southeastern US. International Journal of Life Cycle Assessment 25: 89-104. [CrossRef]

Meyer, Ane Katharina Paarup, Ehiazesebhor Augustine Ehimen, and Jens Bo Holm-Nielsen. 2014. Bioenergy production from roadside grass: A case study of the feasibility of using roadside grass for biogas production in Denmark. Resources, Conservation and Recycling 93: 124-33. [CrossRef]

Meyer, Ane Katharina Paarup, Chitra Sangaraju Raju, S. Kucheryavskiy, and Jens Bo Holm-Nielsen. 2015. The energy balance of utilising meadow grass in Danish biogas production. Resources, Conservation and Recycling 104: 265-75. [CrossRef]

Milazzo, Maria Francesca, F. Spina, Alessandro Vinci, Claudia Espro, and J. C. J. Bart. 2013. Brassica biodiesels: Past, present and future. Renewable and Sustainable Energy Reviews 18: 350-89. [CrossRef]

Moriarty, Patrick, and Damon Honnery. 2019. Ecosystem maintenance energy and the need for a green EROI. Energy Policy 131: 229-23. [CrossRef] 
Murphy, David J., and Charles A. S. Hall. 2010. Year in review-EROI or energy return on (energy) invested. Annals of New York Academy of Sciences 1185: 102-18. [CrossRef] [PubMed]

Murphy, David J., Charles A. S. Hall, and Bobby Powers. 2011. New perspectives on the energy return on (energy) investment (EROI) of corn ethanol. Environment, Development and Sustainability. 13: 179-202. [CrossRef]

Murphy, David J., Michael Carbajales-Dale, and Devin Moeller. 2016. Comparing apples to apples: why the net energy analysis community needs to adopt the life-cycle analysis framework. Energies 9: 917. [CrossRef]

$\mathrm{Ng}$, Poh Khai, and Nalanie Mithraratne. 2014. Lifetime performance of semi-transparent building-integrated photovoltaic (BIPV) glazing systems in the tropics. Renewable and Sustainable Energy Reviews 31: 736-45. [CrossRef]

Palmer, Graham, and Joshua Floyd. 2017. An Exploration of Divergence in EPBT and EROI for Solar Photovoltaics. BioPhysical Economics and Resource Quality 2: 15. [CrossRef]

Perez, M. J. R., H.-C. Kim, V. M. Fthenakis, and A. O. Pereira. 2011. The Environmental Life-Cycle Value Proposition. Paper presented at 40th ASES National Solar Conference, Raleigh, NC, USA, May 17; pp. 941-48.

Piastrellini, Roxana, Alejandro Pablo Arena, and Bárbara Civit. 2017. Energy life-cycle analysis of soybean biodiesel: Effects of tillage and water management. Energy 126: 13-20. [CrossRef]

Pickard, William F. 2017. A simple lower bound on the EROI of photovoltaic electricity generation. Energy Policy 107: 488-90. [CrossRef]

Pleanjai, Somporn, and Shabbir H. Gheewala. 2009. Full chain energy analysis of biodiesel production from palm oil in Thailand. Applied Energy 86: S209-S214. [CrossRef]

Pradhan, Anup, Dev S. Shrestha, Jon Van Gerpen, and James Duffield. 2008. The energy balance of soybean oil biodiesel production: A review of past studies. Transactions of the Asabe 51: 185-94. [CrossRef]

Preston, T. R., and Lylian Rodríguez. 2009. Energy returned on energy invested (EROEI); the case for gasification as a component of an integrated livestock-based farming system. Livestock Research for Rural Development 21: 195.

Price, Lindsay, and Alissa Kendall. 2012. Wind power as a case study: Improving life cycle assessment reporting to better enable meta-analyses. Journal of Industrial Ecology 16: S22-S27. [CrossRef]

Rahimi, Vajiheh, Keikhosro Karimi, Marzieh Shafiei, Reza Naghavi, Benyamin Khoshnevisan, Hossein Ghanavati, Seyed Saeid Mohtasebi, Shahin Rafiee, and Meisam Tabatabaei. 2018. Well-to-wheel life cycle assessment of Eruca Sativa-based biorefinery. Renewable Energy 117: 135-49. [CrossRef]

Rana, Roberto Leonardo, Mariarosaria Lombardi, and Caterina Tricase. 2013. Environmental aspects of bioenergy from microalgae. Paper presented at 21st European Biomass Conference \& Exhibition: Setting the Course for a Biobased Economy, Copenhagen, Denmark, June 3-7; pp. 203-10.

Raugei, Marco, Michael Carbajales-Dale, Charles J. Barnhart, and Vasilis Fthenakis. 2015. "Rebuttal:" Comments on 'Energy intensities, EROIs (energy returned on invested), and energy payback times of electricity generating power plants'-Making clear of quite some confusion. Energy 82: 1088-91. [CrossRef]

Raugei, Marco, Sgouris Sgouridis, David Murphy, Vasilis Fthenakis, Rolf Frischknecht, Christian Breyer, and Ugo Bardi. 2017. Energy Return on Energy Invested (ERoEI) for photovoltaic solar systems in regions of moderate insolation: A comprehensive response. Energy Policy 102: 377-84. [CrossRef]

Restuccia, A., S. Failla, D. Longo, L. Caruso, I. Mallia, and G. Schillaci. 2013. Assessment of energy return on energy investment (EROEI) of oil bearing crops for renewable fuel production. Journal of Agricultural Engineering 44: 539-45. [CrossRef]

Ribeiro, Jorge Miguel Carneiro, Radu Godina, João Carlos de Oliveira Matias, and Leonel Jorge Ribeiro Nunes. 2018. Future Perspectives of Biomass Torrefaction: Review of the Current State-Of-The-Art and Research Development. Sustainability 10: 2323. [CrossRef]

Rocha, Mateus Henrique, Rafael Silva Capaz, Electo Eduardo Silva Lora, Luiz Augusto Horta Nogueira, Marcio Montagnana Vicente Leme, Maria Luiza Grillo Renó, and Oscar Almazán del Olmo. 2014. Life cycle assessment (LCA) for biofuels in Brazilian conditions: A meta-analysis. Renewable and Sustainable Energy Reviews 37: 435-59. [CrossRef] 
Roles, John, Jennifer Yarnold, Juliane Wolf, Evan Stephens, Karen Hussey, and Ben Hankamer. 2020. Charting a Development Path to Deliver Cost Competitive Microalgae-Based Fuels. Algal Research 45: 101721. [CrossRef]

Rye, Craig D., and Tim Jackson. 2018. A review of EROEI-dynamics energy-transition models. Energy Policy 122: 260-72. [CrossRef]

Spath, Pamela L., and Margaret K. Mann. 2000. Life Cycle Assessment of A Natural Gas Combined-Cycle Power Generation System; NREL/TP-570-27715. Golden: National Renewable Energy Laboratory. Available online: https://www.nrel.gov/docs/fy00osti/27715.pdf (accessed on 14 December 2019).

Tareen, Wajahat Ullah Khan, Zuha Anjum, Nabila Yasin, Leenah Siddiqui, Ifzana Farhat, Suheel Abdullah Malik, Saad Mekhilef, Mehdi Seyedmahmoudian, Ben Horan, Mohamed Darwish, and et al. 2018. The Prospective Non-Conventional Alternate and Renewable Energy Sources in Pakistan-A Focus on Biomass Energy for Power Generation, Transportation, and Industrial Fuel. Energies 11: 2431. [CrossRef]

Uusitalo, Ville, Maija Leino, H. Kasurinen, and Lassi Linnanen. 2017. Transportation biofuel efficiencies from cultivated feedstock in the boreal climate zone: Case Finland. Biomass and Bioenergy 99: 79-89. [CrossRef]

Van Duren, Iris, Alexey Voinov, Oludunsin Arodudu, and Melese Tesfaye Firrisa. 2015. Where to produce rapeseed biodiesel and why? Mapping European rapeseed energy efficiency. Renewable Energy 74: 49-59. [CrossRef]

Walmsley, Timothy G., Michael R. W. Walmsley, and Martin J. Atkins. 2017. Energy Return on energy and carbon investment of wind energy farms: A case study of New Zealand. Journal of Cleaner Production 167: 885-95. [CrossRef]

Walmsley, Timothy G., Michael R. W. Walmsley, Petar S. Varbanov, and Jiří J. Klemeš. 2018. Energy Ratio analysis and accounting for renewable and non-renewable electricity generation: A review. Renewable and Sustainable Energy Reviews 98: 328-45. [CrossRef]

Wang, Yu, and Ming-Hsun Cheng. 2018. Greenhouse gas emissions embedded in US-China fuel ethanol trade: A comparative well-to-wheel estimate. Journal of Cleaner Production 183: 653-61. [CrossRef]

Weißbach, Daniel, G. Ruprecht, A. Huke, K. Czerski, S. Gottlieb, and A. Hussein. 2013. Energy intensities, EROIs (energy returned on invested), and energy payback times of electricity generating power plants. Energy 52: 210-21. [CrossRef]

Yeo, Joonho, Shauhrat S. Chopra, Lin Zhang, and Alicia Kyoungjin An. 2019. Life Cycle Assessment (LCA) of Food Waste Treatment in Hong Kong: On-Site Fermentation Methodology. Journal of Environmental Management 240: 343-51. [CrossRef] [PubMed]

Zhang, Li Xiao, Ming Yue Pang, Ji Han, Yuyou Li, and Chang Bo Wang. 2019. Geothermal power in China: Development and performance evaluation. Renewable and Sustainable Energy Reviews 116: 1-8. [CrossRef]

Zhou, Zikai, and Michael Carbajales-Dale. 2018. Assessing the photovoltaic technology landscape: efficiency and energy return on investment (EROI). Energy Environmental Science 11: 603. [CrossRef]

Zupko, Robert. 2019. Life Cycle Assessment of the Production of Gasoline and Diesel from Forest Residues using Integrated Hydropyrolysis and Hydroconversion. International Journal of Life Cycle Assessment 24: 1793-804. [CrossRef]

(C) 2020 by the authors. Licensee MDPI, Basel, Switzerland. This article is an open access article distributed under the terms and conditions of the Creative Commons Attribution (CC BY) license (http://creativecommons.org/licenses/by/4.0/). 